\title{
Modern forensic psychiatric hospital design: clinical, legal and structural aspects
}

\author{
Allan Seppänen ${ }^{1,2^{*}} \mathbb{C}$, lida Törmänen ${ }^{1,3}$, Christopher Shaw ${ }^{4}$ and Harry Kennedy ${ }^{5,6}$
}

\begin{abstract}
Forensic psychiatric care must be provided within the least restrictive setting possible, whilst simultaneously maintaining appropriate levels of security. This presents particular challenges for the design of forensic psychiatric hospitals, which are required to provide both a therapeutic and a safe material environment, often for extended periods of treatment and rehabilitation. By taking into consideration variable trends in psychiatric service provision and myriad clinical, legal and ethical issues, interdisciplinary forensic facility design teams are at the very forefront in implementing the latest developments in medical architecture. Also, although there are significant differences in how forensic psychiatric services are organized around the world, the underlying clinical challenges and increasingly researchbased treatment principles are similar worldwide; it is therefore becoming less acceptable to operate and develop national forensic services without reference to international standards. Accordingly, we here review the literature on what features of forensic psychiatric facilities best serve the needs of those patients who need to rely on them, and we present a systematic and widely applicable approach to the complex and costly challenge of modern forensic psychiatric hospital design.
\end{abstract}

Keywords: Forensic psychiatry, Hospital architecture, Service development

\section{Background}

Forensic psychiatric care aims to improve the mental health and reduce the risk of recidivism of mentally disordered offenders, and other patients with similar complex needs. This must be achieved within the least restrictive setting possible, and with a view to eventual community reintegration, whilst simultaneously maintaining a secure treatment environment [1-3]. However, forensic psychiatric services and the facilities in which they are provided are defined and governed in different ways across the world: some countries have issued detailed criteria for different levels of secure care, including building design and material specifications [4-6], whereas in other countries, security is much more loosely defined, and has essentially developed over time along with clinical practices [7-9]. This is mainly due to variation in the specifics of legislation and the particular ways in which forensic

\footnotetext{
*Correspondence: allan.o.seppanen@hus.fi

${ }^{1}$ Department of Psychoses and Forensic Psychiatry, Helsinki University

Hospital, Helsinki, Finland

Full list of author information is available at the end of the article
}

mental health systems are operationalized in different countries, as the underlying clinical issues and principles remain relatively similar across countries [10-13].

Accordingly, the placement and treatment of the forensic patient population has been an issue of debate within the criminal justice systems in Western Europe $[14,15]$. In addition to dedicated forensic hospitals and units, mentally disordered offenders may be placed in general psychiatric hospitals, prison hospitals and, less commonly, psychiatric wards in general hospitals. In some EU member states, not only mentally disordered offenders, but other aggressive, violent or otherwise highrisk patients referred from general psychiatric facilities may be admitted to forensic facilities [12, 14]. This can cause strain between services, as general psychiatry may develop a tendency towards outsourcing to forensic psychiatry the treatment-particularly coercive interventions - of patients viewed as somehow troublesome [16] and, on the other hand, forensic patients may be seen to block beds needed for patients with more acute presentations [17]. In any case, interaction between general psychiatric services and forensic psychiatry is essential, and 
inevitable: the majority of patients in forensic units have had previous contact with general psychiatric services and will require transfer back to communal care at some point in their psychiatric treatment [18].

Deinstitutionalization, particularly in Western Europe and the United States, has gradually reformed psychiatric health care; many large, institution-like hospitals have been withdrawn from use or modified since the 1950s [19] and many units face continual pressure to decrease the number of remaining beds. The trend is being reinforced by developments in information technology, which are continually offering new treatment possibilities and environments for psychiatric care [20]. Arguably, the trend towards deinstitutionalization of general psychiatric patients has contributed to increasing the number of placements in forensic psychiatric facilities and raising the demand for supported housing, in a process of re- or trans-institutionalization $[17,19,21,22]$. This is not a new area of enquiry; the relationship between the decrease in general psychiatric bed numbers and the expansion of the prison population suffering from mental health issues has been a focus of intense research and debate since the 1930's, when Penrose introduced his "Law", according to which the size of the prison population is inversely related to the available number of psychiatric hospital beds [23]. Some studies have indeed found a correlation between the decrease in psychiatric bed numbers and an increase in mentally ill prisoners [24] but further research is needed to establish causality [25, 26]. It has been suggested, for instance, that other societal factors in the USA and Western Europe, rather than deinstitutionalization in itself, are responsible for the rising number of prisoners with psychiatric problems. Significant contributory factors may be the increase in homelessness, illegal drug use, changes in mental healthcare funding [24], and decreased numbers of forensic psychiatric pre-sentence examinations [27]. Furthermore, a cross-sectional study by Large and Nielssen [28] found no association between the size of the prison population and psychiatric hospital bed numbers in high-income countries, whereas positive correlations were found in low- and middle-income countries.

However, while ongoing trends in psychiatric service systems indeed stress deinstitutionalization and outpatient care, for some patients a restricted and safe environment is an essential feature of their mental health care regime, at least at certain stages of their illness, in order to maintain both their own and public safety. Here, we review the current literature on what aspects of forensic psychiatric facilities best serve the needs of those patients who still need to rely on them, and we attempt to define a structured way of approaching the complex and costly challenge of forensic psychiatric facility design. For the purpose of this review, we define a forensic psychiatric facility as a healthcare institution into which patients have been diverted from either correctional services, typically due to criminal irresponsibility issues or enduring post-sentencing mental illness, or general psychiatric services, typically due to serious risk of inter- or intrapersonal violence.

\section{General remarks on psychiatric hospital design: history, ideology, evidence}

According to Horsburgh [29], the architectural design of psychiatric facilities and the quality of living space are essential aspects of the healing process, and thus affect the outcome of medical care. Previous studies have highlighted the importance of a safe physical environment that enables intensive, stabilizing treatment together with reasonable privacy and observability [30]. Dijkstra, Pieterse [31] conclude that while the general notion of the healthcare environment affecting the wellbeing of patients is supported by the literature, conclusive evidence is still limited as to specific environmental factors. Others argue that research findings and clinical conjecture have consistently supported the idea of the environment playing a significant role in patient and staff functioning in psychiatric hospital settings, but that this fact has even yet to be fully recognized and implemented in hospital design. Indeed, the development of psychiatric institutions has been characterised as coercive, confining and their buildings as the embodyment of discipline and control, the exercise of power over the socially deviant [32]. Yet modern design of built environments can create an engineered sense of shared safety and ownership of one's living space $[33,34]$ and even the earliest hospitals for the mentally ill were established with caring and compassionate ideals [35]. Typically, the various designers and theorists placed great emphasis on the same elements of architecture, staffing and activities: physical, relational and procedural safety and security as described below, with an organisational and managerial vision and overview [36, 37]. In what may be a series of historical cycles, these elements became subsequently victims of the social processes that supported them [38]: a growing awareness of the social context of mental illness [39] led 
on to a recognition of the anthropological micro-cultures of closed institutions $[40,41]$ and the policy decision to close the asylums on the grounds that they were inherently harmful and community care would prevent institutionalisation' followed [42]. In practice, it was evident from an early stage that this was not a coherent theory or policy, and the practice of decarceration was not equal to a liberation or an improvement in quality of life $[19,43]$. As the historical cycle has continued to turn, there has been first a new interest in reform and attention to therapeutic environment and regime $[44,45]$, a review of the culture and exercise of 'power and praxis' in psychiatric wards and hospitals [46] and a late, but welcome, interest in the primary therapeutic power of the hospital environment itself [29, 31, 47-52], in which nature and art play an important part [53].

All in all, one of the most consistent recommendations in the body of literature on psychiatric hospital design is to reduce the institutional feel of the facility, and instead create a more homelike environment [54]. This must be taken into consideration from the earliest stages of the design process, as architectural features, such as the layout or physical plan, size and shape of rooms, and the placement of windows, are relatively immutable aspects of the hospital building [50]. In contrast, interior design features are less fixed; furnishings, basic consumer appliances (e.g. televisions, telephones, computers), colors, artwork and the décor of patient rooms [50] are easily modifiable according to purpose and individual choice. Also ambient features, such as sunlight, views of nature and reduction in noise, have been shown to be helpful in psychiatric recovery $[31,55]$. Also, fresh air, good ventilation, neutral odours, and natural daylight in patient rooms can promote the recovery of psychiatric patients with severe depression; in general, soft, indirect and pervasive lighting should be provided [54]. Providing outdoor gardens and rooms with views of nature might shorten recovery times, reduce need for pain medication, and mitigate patients' psychological distress by serving as positive distractions $[47,54]$. These findings are consistent with research indicating that views of nature produce higher levels of relaxation as compared with urban scenes [48]. According to Edgerton, Ritchie [33], colour selection, live plants, floor space, and furniture arrangement can foster social interaction, but at the same time help maintain privacy. This is an important point, as patients should be able to regulate their own level of social contact while in psychiatric care [52, 54].
Thus, although the trend towards deinstitutionalizing psychiatric patients remains strong, the modern psychiatric unit continues to have an important role to play as a stable and secure centre for treatment, research, and rehabilitation [51]. This is particularly true of forensic psychiatric units.

\section{Forensic facilities: therapy integrated with security}

In the UK, as an example, the current forensic psychiatric services began to form and diverge from earlier settings in the early 1960s. Regional secure units were set up within general psychiatric hospitals from the 1980s onwards, further stimulating debate about how health and social services should provide for mentally ill offenders and non-offenders with similar needs. The Reed Report [56] made hundreds of recommendations for streamlining forensic service provision, including that security measures should be no stricter than warranted by the risk posed by patients to themselves or to others. Accordingly, Eggert, Kelly [49] emphasize that the cardinal principle in the design of psychiatric facilities is the mitigation of the risk of self-harm or harm to others. Nowhere is this more true than in forensic psychiatric facilities.

Indeed, risk issues lie at the very core of forensic psychiatric practice, as the environment must be safe and stable before any real treatment progress can take place [57]. In a forensic facility, various forms of treatmentand safety-compromising risks are present which require correlative management strategies. For instance, the risk of violence and self-harm requires adequate numbers of well-trained clinical staff [58] and a culture of fluent communication of risk observation [59]. Also, the treatment facilities must be designed in a way that enables staff to observe all activity that occurs in the interior areas, except, for reasons of privacy, the patients' rooms [30], which in turn must be designed to minimize ligature risk [60]. The risk of escape, on the other hand, requires a well designed perimeter and well thought-out procedures regarding passage in and out of the secure facility [2]. An unsuitable physical environment can severely impair care quality and the feeling of safety, and might damage the person-centered therapeutic process $[45,61]$.

\section{The three aspects of security}

In order to overcome the risk-related challenges set out above, the Reed Report distinguishes three aspects of security: physical security, relational security and 
procedural security [56]. Physical security covers aspects of environmental and building design that include safety and restraint, such as safety-windows, locks, walls and alarm systems. Relational security focuses on a more qualitative viewpoint: the patient-professional relationship, knowledge of specific patients' history and a general understanding of the forensic patient population. Procedural security focuses on policies and procedures that maintain safety and security, e.g. search protocols and surveillance of restricted items [56, 59, 62].

According to Kennedy [63], relational security is by far the most important element in maintaining a therapeutically safe and secure setting and furthering of patients' therapeutic progress. However, the physical environment affects the way relational security is delivered [59]. Thus, security measures and therapeutic issues are closely linked; neither should be dealt with in isolation. Security provides a positive and supportive framework within which clinical care and therapy are safely delivered. Good security and effective therapy should be seen as integrated concepts rather than opposite ends of a spectrum, keeping in mind that secure psychiatric facilities are distinct and separate from prisons; the building and site layout must be planned in a sensitive and balanced way. Thus, a therapeutic forensic hospital milieu must include the therapeutic use of security, enabling a better quality of life through effective, individualized medical interventions and rehabilitative social interaction, such as multidisciplinary teamwork, occupational therapy and other meaningful activities [15].

With these factors in mind, the UK Department of Health has set out binding principles and security requirements for designing secure inpatient settings in Great Britain in the Environmental Design Guide [4]. A safe and therapeutic environment, which is fit for purpose and takes into account that patients may be in residence for extended periods, is a key precondition for relational security to develop. Thus, the Environmental Design Guide lays out meticulous instructions for the planning and design of individual $15 \mathrm{~m}^{2}$ en-suite bedrooms, interview or consulting rooms for one-to-one and group activities, visiting areas, day rooms, and therapeutic areas for occupational therapy, sports and exercise. The guide states that security and safety for patients, staff and public must always be taken into consideration while designing and building windows, doors, walls and fences. Materials accessible to patients should be non-breakable.
Windows must provide daylight and ventilation, but at the same time maintain security, and be resistant to scratches and damage. Doors and entrances, electronic systems for personal security, internal walls and floor surfaces, ceilings, lighting, corridors, pitched roofs, fire precautions and fences along the external perimeters all have their own specifications. The guide also recommends incorporating a de-escalation area into the site design-a low-stimulus environment for patients to calm down, which acts as a step between seclusion facilities and the ward area. Bathrooms and lavatories should be designed to reduce the risk of suicide; thus, all ductwork, plumbing and pipe-work should be concealed. The guide also includes testing schedules for building materials and information about the installation and use of CCTV. For staff, it recommends the provision of spaces for confidential working, learning and development, eating and resting, as well as changing rooms and locker facilities [4].

\section{Urban vs. rural setting}

Various historical and geographical factors have contributed to the fact that some countries have secure units located in densely populated urban areas, whereas in others, forensic facilities are more often situated in remote locations.

Urban forensic services can provide various forms of rehabilitative stimuli which are not so easily accessible in a more rural environment. But this in turn raises issues concerning the safety of both the patients themselves and people around them: access to drugs and alcohol, and opportunities for antisocial interaction are all factors to be taken into consideration. Regardless of the setting, buildings must be secure, so as to facilitate the treatment model and care pathway, and simultaneously to promote community engagement and recovery. Using high-quality construction materials throughout the building, and being mindful of how operational and structural aspects of the hospital building integrate into its environment, will help to improve outcomes for patients [4].

Proposals to build a forensic facility in an urban area tend to raise media attention, and opposition from local residents concerned about the risk of violence and criminal activity in their communities (As an example see [64]). However, it has been demonstrated that medium-security units do not have a measurable impact on serious crime rates in their immediate localities [65]. 
Accordingly, it is recommended to locate medium- and low-security units as close as possible to general population services, so as to enable patients to maintain contact with their family and friends, general psychiatric services and out-patient care, and the community at large [5]. Although intoxicants, criminality and conditions favourable to recidivism are less prevalent in areas with low population density [66], these risks must still be invariably factored in as potential key destabilizers in any setting. Thus, monitoring and intervening in antisocial activities, including the use and trading of drugs, are key requirements in any forensic service provision.

\section{Privacy vs. spaces for social interaction}

According to Karlin and Zeiss [54], accommodating patients in single-occupancy rooms enhances their sense of autonomy and might promote participation in therapeutic activities. On the other hand, Dvoskin, Radomski [30] cited enhanced opportunities for social interaction with other patients and possible cost savings as advantages of multiple-occupancy rooms, but increased risk of violence due to forced co-habitation as a drawback. Also, having an integrated toilet and sink in every patient room has its benefits and drawbacks; the advantage of en suite rooms is that they are more convenient for patients and they make the nighttime corridor surveillance easier. On the other hand, en suite rooms are more expensive than "dry rooms", and might be reminiscent of a prison environment. There are also concerns that spending too much time in their rooms might hinder patients' rehabilitation [30]. En suite designs should take fully into account the risks posed by potentially destructive, polydipsic and suicidal patients; for example, water supply must be adjustable from outside patients' rooms. However, all in all, recent recommendations favour en suite patient rooms $[4,6]$, as the benefits provided by privacy and the chance to personalize one's immediate surroundings outweigh possible drawbacks.

\section{Seclusion and restraint}

National mental health laws in most countries stipulate that psychiatric patients who exhibit dangerous and difficult-to-treat behaviors can be subjected to coercive measures, such as seclusion $[67,68]$, if specific criteria are met. However, being subjected to coercive measures can cause significant displeasure [61]_even when considered necessary by patients themselves [69] — and might be experienced as traumatic and unjust [70]. Naturally, it is preferable to prevent or reduce the risk of patients' displaying the kind of behaviours that warrant coercive measures being deployed. Patients should therefore have access to quiet, conveniently located areas, where they can relax and aggression can de-escalate, such as secure garden spaces which patients can enter at will [61].

As for the location of seclusion rooms, placing them near to the center of activities might promote safety, whereas locating them closer to the periphery might soothe the ward environment but reduce the immediate availability of staff. Hence, seclusion rooms should be placed near nursing stations, but outside the main corridors and dayrooms [54]. Their construction should be highly robust, in order to withstand repeated destructive violence without posing a risk for the patient or staff, whilst at the same time maintaining the dignity and comfort of the secluded patient $[4,6,71]$.

\section{Managing on-site substance misuse, escapes and absconding}

Most forensic inpatients suffer from psychotic illness with comorbid personality disorder and/or substance misuse [65]. Alcohol and drug misuse aggravate the symptoms of mental illness, increase impulsivity and risky behavior, and reduce the efficacy of treatment [72]. Well-functioning physical and procedural security, such as fences, check-ups and staff observation, in addition to efficient relational security, are ways to moderate alcohol and drug misuse in a ward setting [73]. However, legal constraints may hinder the development of routine security protocols due to the various ways in which the concept of "blanket restriction", i.e. the routine application of rules or policies that infringe upon a patient's right to self-determination, without individual risk assessments to justify their application $[74,75]$, is defined in national legislation and interpreted by respective medico-legal authorities. On the other hand, forensic units are expected to maintain an appropriate level of security, and it has been shown that absconding is most likely to occur when patients themselves feel that wards are unsafe [76]. Also, an increase in bed numbers is associated with a rise in the incidence of escapes, as is-unsurprisingly-a lower perimeter fence [77]. 


\section{Human rights}

According to Gradillas, Williams [65], the development of secure forensic inpatient facilities is vital to the provision of humane and effective treatment of the mentally ill in any society. Accordingly, in recent years, human rights have become an increasingly pivotal focus of public debate. People with mental illness, who pose a risk to themselves and to others, are some of the most vulnerable members of society, and special attention must be paid to protecting their rights [78]. The mentally ill offender has a dual position: as a patient in need of treatment and as a person subject to the criminal justice system. In many European countries, continual attempts are being made to create a better legal balance by ensuring the right to adequate treatment for all individuals, while at the same time maintaining public safety [14]. Although the clinical challenges that forensic services face recur across different countries, variability in national legislation causes significant differences at the service-patient interface, even in countries that have ratified and subscribe to the same international human rights legislation and are subject to the same monitoring bodies [68].

A central concept that arises in any consideration of these issues is that of the "inherent dignity" that the Universal Declaration of Human Rights [79] ascribes to all persons [80]. The ways that inherent human dignity can be upheld by mental health services can generally be approached in two ways: by defining dignity as empowerment, or as constraint. The first conceptualization defines dignity as a right to self-determination, rather than having limits placed on one's free choices. The latter, on the other hand, defines dignity as an objective value that reaches beyond the free choices of an individual; thus, a person's dignity can be compromised by his own actions regardless of whether the individual chose to act as he did at the given time [81]. Also, constraining one individual can be seen as maintaining the dignity of another, if the latter is somehow threatened or, indeed, damaged by the actions of the former. As these concepts of dignity are obviously not mutually exclusive, an ideal balance-although difficult to attain-must be striven for when planning all aspects of forensic services, from building design to service policies and clinical treatment measures.

\section{Template for a forensic facility design brief}

Taking into consideration the myriad clinical, legal and architectural considerations, planning a new forensic hospital is a highly complex process. However, as an integral part of a well-functioning forensic service, it is a clinical and ethical necessity in any society. Despite variability in national legislation and socio-demographic factors affecting various national forensic patient populations, in the following design template we attempt to capture general, internationally applicable design principles (Table 1).

\section{Discussion}

The process of deinstitutionalization of psychiatric care in many Western nations is coming to be understood, rather, as a more complex process of trans- or reinstitutionalization from traditional psychiatric hospitals to supported housing, prisons and, not least, forensic psychiatric units $[19,22,27]$. As a result, authorities in many countries have come under increased pressure to both expand and update their forensic psychiatric services [17, 90-93], so as to respond more effectively to the needs of mentally ill offenders and other psychiatric patients with similar needs. Simultaneously, an increased focus on patient and carer rights and involvement has emerged throughout the development and implementation of healthcare services $[94,95]$, as have international monitoring standards to uphold human rights within psychiatric institutions [68]. Thus, it is becoming less acceptable to operate national forensic services without reference to international standards or without knowing what practices are employed elsewhere in the world $[11,96]$.

Developments in international trends, societal attitudes towards mental health issues, and the design of psychiatric care environments are closely intertwined. This is reflected in modern evidence-based architectural hospital design, which is founded on research into the link between characteristics of the care environment and patient recuperation and well-being [97]. Also, the way in which society defines its basic ethical principles changes over time, and it is a matter of continual ethical, clinical and legal debate where the line between security and therapy should be drawn at any given time. Thus, changing views on treatment must be matched by changes in the operational models of healthcare services, which are themselves bound up with the design of hospital buildings [51].

\section{Conclusions}

Forensic psychiatric hospitals are high-cost, low-volume medical institutions, which are required to provide both therapeutic and safe and secure material environments $[2,4,6,59,68]$; thus they are at the very forefront in implementing the latest developments in medical architecture. Although the evidence base for many interventions within forensic psychiatry is still weak, these hospitals do provide an essential, specialized service for mentally disordered offenders and others with similar needs, both in terms of healthcare and decreasing 


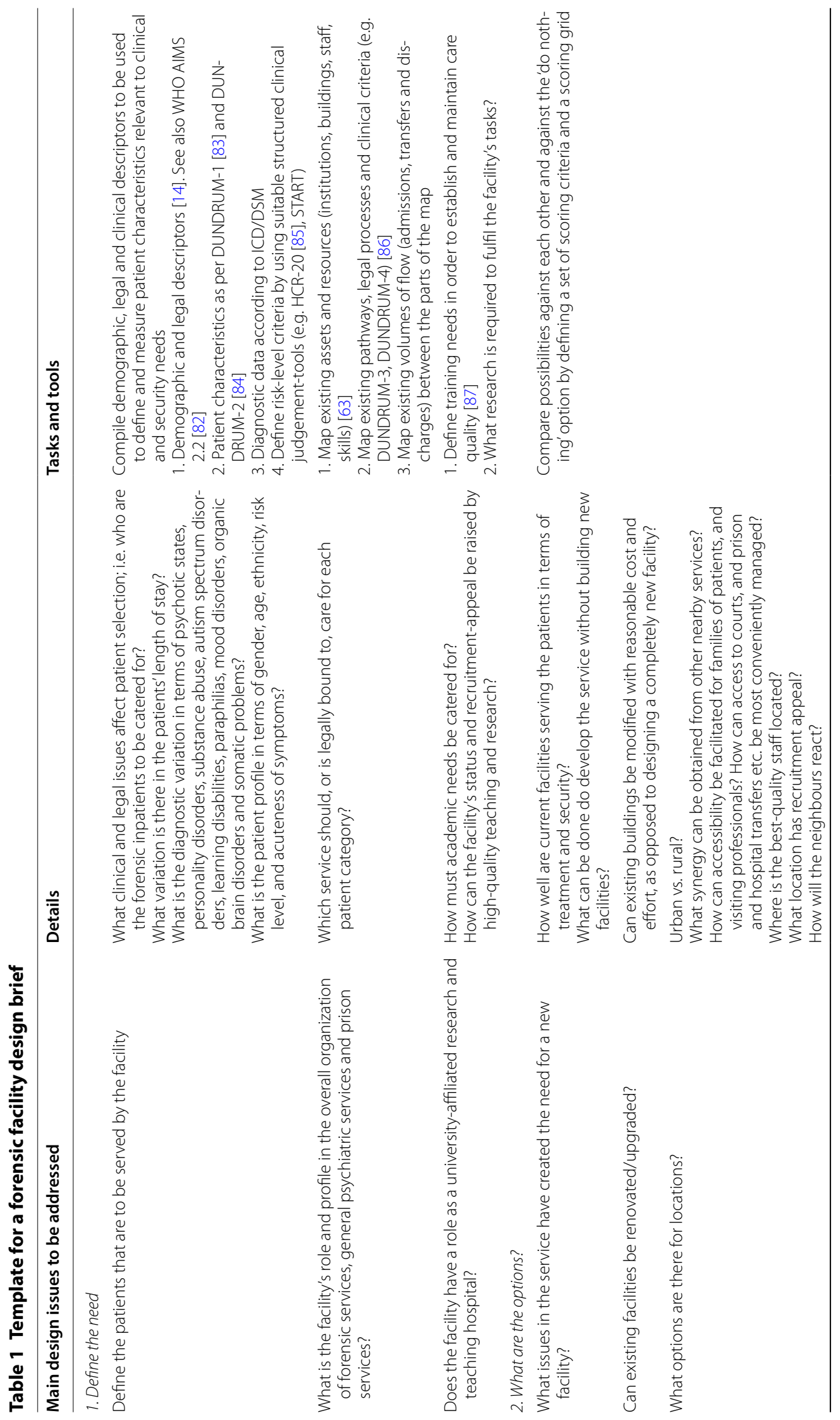


Seppänen et al. Int J Hent Health Syst <wide> <wide>(2018) 12:58

Page 8 of 12

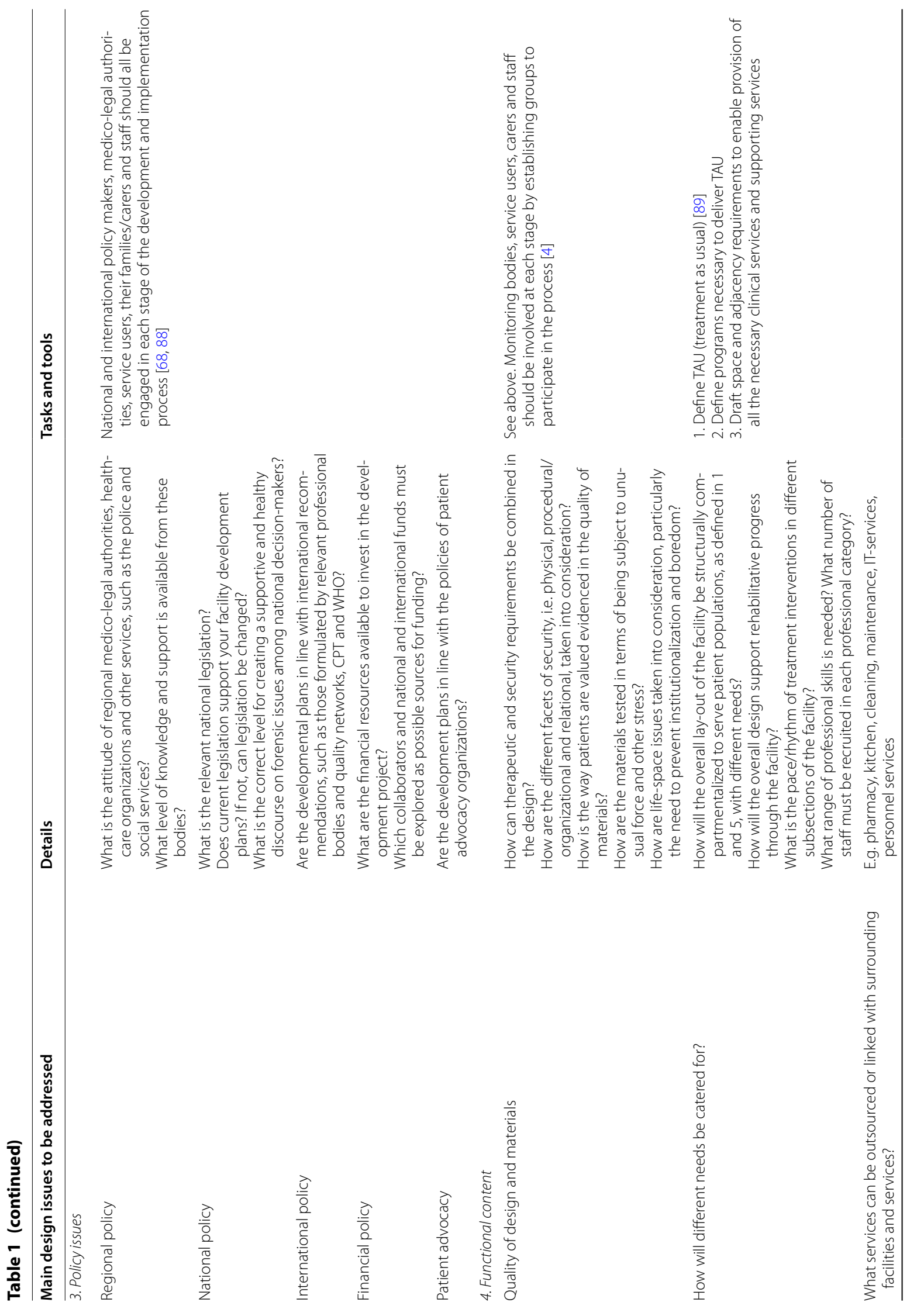




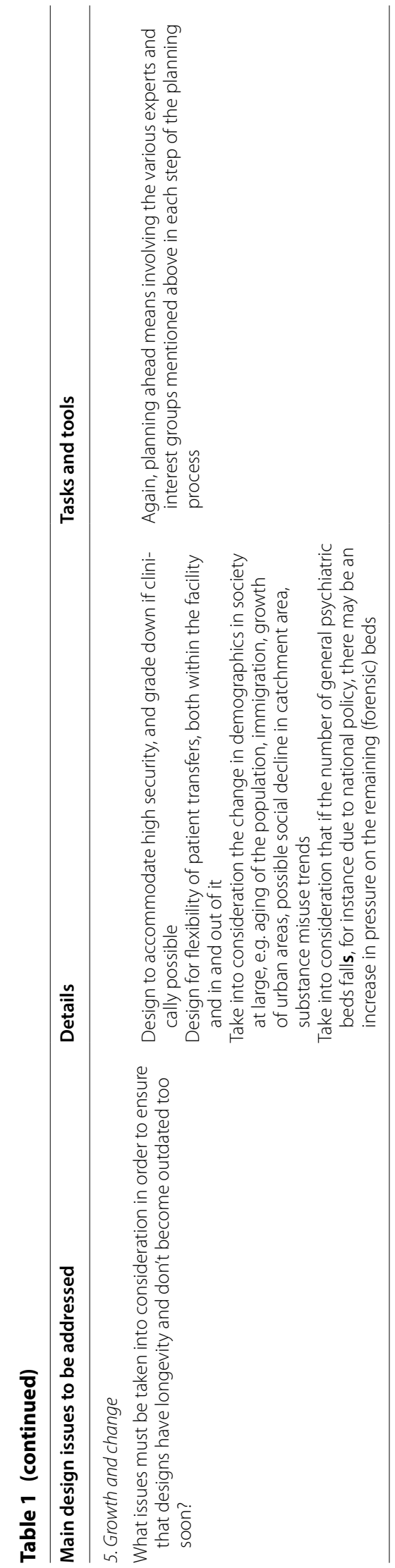


the risk of re-offending [15, 98]. Only by entering into an open, yet structured and coherent, international research-driven discussion with clinicians, scientists, architects, policy-makers and medico-legal authorities, can we continue to raise the standard of our services, and the facilities in which they are provided.

\section{Authors' contributions}

AS, CS and HK designed the forensic facility design brief. IT and HK searched and compiled the background literature. AS constructed the manuscript. AS, IT, CS and HK contributed to the revision and reworking of the manuscript. All authors read and approved the final manuscript.

\section{Author details \\ ${ }^{1}$ Department of Psychoses and Forensic Psychiatry, Helsinki University Hospital, Helsinki, Finland. ${ }^{2}$ Vanha Vaasa Hospital, Vaasa, Finland. ${ }^{3}$ Department of ICT Psychiatry and Psychosocial Treatments, Helsinki University Hospital, Helsinki, Finland. ${ }^{4}$ Medical Architecture and Art Projects Ltd, London, UK. ${ }^{5}$ Department of Psychiatry, Trinity College, Dublin, Ireland. ${ }^{6}$ National Forensic Mental Health Service, Central Mental Hospital, Dundrum, Dublin, Ireland.}

\section{Acknowledgements}

We thank Ann Seppänen, B.A., M.Ed., for critical reading and language revision of this manuscript.

\section{Competing interests}

The authors declare that they have no competing interests.

\section{Availability of data and materials}

Data sharing is not applicable to this article as no datasets were generated or analysed during the current study.

\section{Consent for publication}

Not applicable.

\section{Ethics approval and consent to participate} Not applicable.

\section{Funding}

COST Action IS1302 (Towards an EU research framework on forensic psychiatric care) provided funding for a training school on Modern forensic in-patient facility design standards, where the formulation of this article commenced.

\section{Publisher's Note}

Springer Nature remains neutral with regard to jurisdictional claims in published maps and institutional affiliations.

Received: 31 July 2018 Accepted: 11 October 2018

Published online: 20 October 2018

\section{References}

1. Nedopil N. The role of forensic psychiatry in mental health systems in Europe. Crim Behav Ment Health. 2009;19(4):224-34.

2. Royal College of Psychiatrists. Standards for medium secure services, vol. 178. London: Quality Network for Forensic Mental Health Services; 2014 p. 1-50.

3. Robertson P, Barnao M, Ward T. Rehabilitation frameworks in forensic mental health. Aggress Violent Behav. 2011;16(6):472-84.

4. Department of Health. Environmental design guide: medium secure services. London: Department of Health; 2011. p. 1-44.

5. Department of Health. Design guide: medium secure psychiatric units. London: Department of Health; 1993. p. 1-42.

6. Department of Health. High secure building design guide: overarching principles. London: Department of Health; 2010. p. 1-16.

7. Eronen M, Repo E, Vartiainen H, Tiihonen J. Forensic psychiatric organization in Finland. Int J Law Psychiatry. 2000;23(5-6):541-6.
8. Njenga FG. Forensic psychiatry: the African experience. World Psychiatry. 2006;5(2):97.

9. Abdalla-Filho E, Bertolote JM. Forensic psychiatric systems in the world. Rev Bras Psiquiatr. 2006;28(2):56-61.

10. Edworthy R, Sampson S, Vollm B. Inpatient forensic-psychiatric care: legal frameworks and service provision in three European countries. Int J Law Psychiatry. 2016:47:18-27.

11. Ogloff JR, Roesch R, Eaves D. International perspective on forensic mental health systems. Int J Law Psychiatry. 2000;23(5-6):429-31.

12. Sampson S, Edworthy R, Völlm B, Bulten E. Long-term forensic mental health services: an exploratory comparison of 18 European countries. Int J Forensic Ment Health. 2016;15(4):333-51.

13. Ibishi NF, Musliu NR, Hundozi Z, Citaku K. Prevalence of the hospitalisation of mentally ill offenders in the Forensic Unit of the Clinic of Psychiatry in Pristina over a three-year period and long-term strategy implications for the management of the Forensic Mental Health System Service. Med Sci Law. 2015;55(3):201-7.

14. Salize HJ, Dressing H. Placement and treatment of mentally disordered offenders: legislation and practice in the European Union. Lengerich: Pabst Science Publishers; 2005.

15. Vollm BA, Clarke M, Herrando VT, Seppanen AO, Gosek P, Heitzman J, et al. European Psychiatric Association (EPA) guidance on forensic psychiatry: evidence based assessment and treatment of mentally disordered offenders. Eur Psychiatry. 2018;51:58-73.

16. de Tribolet-Hardy F, Habermeyer E. Schizophrenic patients between general and forensic psychiatry. Front Public Health. 2016;4:135.

17. Mollerhoj J, Stolan LO, Brandt-Christensen M. A thorn in the flesh? Forensic inpatients in general psychiatry. Perspect Psychiatr Care. 2016;52(1):32-9.

18. Gordon H, Lindqvist P. Forensic psychiatry in Europe. Psychiatr Bull. 2007:31:421-4

19. Priebe S, Badesconyi A, Fioritti A, Hansson L, Kilian R, Torres-Gonzales $F$, et al. Reinstitutionalisation in mental health care: comparison of data on service provision from six European countries. BMJ. 2005;330(7483):123-6.

20. Bhugra D, Tasman A, Pathare S, Priebe S, Smith S, Torous J, et al. The WPA-Lancet Psychiatry Commission on the future of psychiatry. Lancet Psychiatry. 2017:4(10):775-818.

21. Kramp P, Gabrielsen G. Forensic patients in Denmark 2000-2004. Ugeskr Laeger. 2005;167(47):4469-72.

22. Chow WS, Priebe S. How has the extent of institutional mental healthcare changed in Western Europe? Analysis of data since 1990. BMJ Open. 2016;6(4):e010188.

23. Penrose LS. Mental disease and crime: outline of a comparative study of European statistics. Br J Med Psychol. 1939;8:1-15.

24. Winkler P, Barrett B, McCrone P, Csemy L, Janouskova M, Hoschl C. Deinstitutionalised patients, homelessness and imprisonment: systematic review. Br J Psychiatry. 2016;208(5):421-8.

25. Kalapos MP. Penrose's law, methodological challenges and call for data. Int J Law Psychiatry. 2016:49:1-9.

26. Bluml V, Waldhor T, Kapusta ND, Vyssoki B. Psychiatric hospital bed numbers and prison population sizes in 26 European countries: a critical reconsideration of the penrose hypothesis. PLOS ONE. 2015;10(11):e0142163.

27. Juriloo A, Pesonen L, Lauerma H. Knocking on prison's door: a 10-fold rise in the number of psychotic prisoners in Finland during the years 2005-2016. Nord J Psychiatry. 2017;71(7):543-8.

28. Large MM, Nielssen O. The Penrose hypothesis in 2004: patient and prisoner numbers are positively correlated in low-and-middle income countries but are unrelated in high-income countries. Psychol Psychother. 2009;82(Pt 1):113-9.

29. Horsburgh CR Jr. Healing by design. N Engl J Med. 1995;333(11):735-40.

30. Dvoskin JA, Radomski SJ, Bennett C, Olin JA, Hawkins RL, Dotson LA, et al. Architectural design of a secure forensic state psychiatric hospital. Behav Sci Law. 2002;20(5):481-93.

31. Dijkstra K, Pieterse M, Pruyn A. Physical environmental stimuli that turn healthcare facilities into healing environments through psychologically mediated effects: systematic review. J Adv Nurs. 2006;56(2):166-81.

32. Foucault M. Discipline and punish: the birth of the prison. New York: Pantheon Books; 1977. 
33. Edgerton E, Ritchie L, McKechnie J. Objective and subjective evaluation of a redesigned corridor environment in a psychiatric hospital. Issues Ment Health Nurs. 2010;31(5):306-14.

34. Newman O. Defensible space. New York: Macmillan; 1972.

35. Malcolm E. Swift's hospital: a history of St Patrick's Hospital, Dublin, 1746-1989. Dublin: Gill and Macmillan; 1989.

36. Kirkbride TS. On the construction, organization, and general arrangements of hospitals for the insane. Philadelphia: Pennsylvania Hospital for the Insane; 1854.

37. Burdett HC. Hospitals and asylums of the World. London: J. \& A. Churchill; 1891.

38. Hunter RA, Macalpine I. Psychiatry for the poor. London: Dawsons Pall Mall; 1974.

39. Faris REL, Dunham HW. Mental disorders in urban areas: an ecological study of schizophrenia and other psychoses. Oxford: University of Chicago press; 1939.

40. Scull AT. Museums of madness: the social organisation of insanity in nineteenth-century England. London: Allen Lane; 1979.

41. Goffman E. Asylums: essays on the social situation of mental patients and other inmates. New York: Anchor Books; 1961.

42. Hall P, Brockington I. The closure of mental hospitals. London: Gaskell/ Royal College of Psychiatrists; 1991.

43. Scull AT. Decarceration: community treatment and the deviant—a radical view. New Jersey: Prentice Hall; 1977.

44. Kaye C, Franey A. Managing high security psychiatric care. London: Jessica Kingsley Publishers; 1998.

45. Alexiou E, Degl'Innocenti A, Kullgren A, Wijk H. The impact of facility relocation on patients' perceptions of ward atmosphere and quality of received forensic psychiatric care. J Forensic Leg Med. 2016;42:1-7.

46. Bartlett A. Secure lives: the meaning and importance of culture in secure hospital care. Oxford: Oxford University Press; 2016

47. Ulrich RS. View through a window may influence recovery from surgery. Science. 1984;224(4647):420-1.

48. Ulrich RS, Simons RF, Losito BD, Fiorito E, Miles MA, Zelson M. Stress recovery during exposure to natural and urban environments. J Environ Psychol. 1991;11(3):201-30.

49. Eggert JE, Kelly SP, Margiotta DT, Hegvik DK, Vaher KA, Kaya RT. Personenvironment interaction in a new secure forensic state psychiatric hospital. Behav Sci Law. 2014;32(4):527-38

50. Harris B, McBride G, Ross C, Curtis L. A place to heal environmental sources of satisfaction among hospital patients. J Appl Soc Psychol. 2002;32(6):1276-99.

51. Cederström H, Seppänen A. Designing the modern psychiatric hospital: environment as therapy. Nord Psychiatr. 2017;2:6-8.

52. Ulrich RS, Bogren L, Gardiner SK, Lundin S. Psychiatric ward design can reduce aggressive behavior. J Environ Psychol. 2018;57:53-66.

53. Hickman C. Therapeutic landscapes: a history of English hospital gardens since 1800. Manchester: Manchester University Press; 2013.

54. Karlin BE, Zeiss RA. Best practices: environmental and therapeutic issues in psychiatric hospital design: toward best practices. Psychiatr Serv. 2006:57(10):1376-8

55. Sine DM, Hunt JM. Following the evidence toward better design. Behav Healthc. 2009:29(7):45-7.

56. Reed J. The development of forensic psychiatric services. In: Clark T, Rooprai DS, editors. Practical forensic psychiatry. London: Hodder Arnold; 2011. p. 3-4.

57. Crichton JHM. Defining high, medium, and low security in forensic mental healthcare-the development of the Matrix of Security in Scotland. J Forensic Psychiatry Psychol. 2009;20(3):333-53.

58. Care Quality Commission. Brief guide: staffing levels on mental health wards. London: Care Quality Commission; 2016. p. 1-3. https://www. cqc.org.uk/sites/default/files/CQC\%20mental\%20health\%20brief\%20gui de\%202\%20-\%20staffing\%20levels\%20on\%20mental\%20health\%20war ds.pdf.

59. Royal College of Psychiatrists. Your guide to relational security: see think act. 2nd ed. London: Quality Network for Forensic Mental Health Services; 2015. p. 1-52.

60. Hunt IM, Windfuhr K, Shaw J, Appleby L, Kapur N, National Confidential Inquiry into $S$, et al. Ligature points and ligature types used by psychiatric inpatients who die by hanging: a national study. Crisis. 2012;33(2):87-94.
61. Van Der Merwe M, Muir-Cochrane E, Jones J, Tziggili M, Bowers L. Improving seclusion practice: implications of a review of staff and patient views. J Psychiatr Ment Health Nurs. 2013;20(3):203-15.

62. Jobbins C, Abbott B, Brammer L, Doyle M, McCann G, McLean R. Executive summary. Best practice guidance: specification for adult mediumsecure services. London: Department of Health; 2007. p. 1-24.

63. Kennedy HG. Therapeutic uses of security: mapping forensic mental health services by stratifying risk. Adv Psychiatr Treat. 2002;8:433-43.

64. Belcher L. Over 200 absconders from Hackney's John Howard Centre in last 13 years. London: Hackney Citizen; 2014.

65. Gradillas V, Williams A, Walsh E, Fahy T. Do forensic psychiatric inpatient units pose a risk to local communities? J Forensic Psychiatry Psychol. 2007;18(2):261-5

66. O'Neill C, Kelly A, Sinclair H, Kennedy H. Deprivation: different implications for forensic psychiatric need in urban and rural areas. Soc Psychiatry Psychiatr Epidemiol. 2005:40(7):551-6.

67. Cullen AE, Bowers L, Khondoker M, Pettit S, Achilla E, Koeser L, et al. Factors associated with use of psychiatric intensive care and seclusion in adult inpatient mental health services. Epidemiol Psychiatr Sci. 2018:27(1):51-61.

68. CPT. Means of restraint in psychiatric establishment for adults (Revised (PT standards). Strasbourg: Council of Europe, European Committee for the Prevention of Torture and Inhuman or Degrading Treatment or Punishment; 2017.

69. Keski-Valkama A, Koivisto A-M, Eronen M, Kaltiala-Heino R. Forensic and general psychiatric patients' view of seclusion: a comparison study. J Forensic Psychiatry Psychol. 2010;21(3):446-61.

70. Askola R, Nikkonen M, Paavilainen E, Soininen P, Putkonen H, Louheranta O. Forensic psychiatric patients' perspectives on their care: a narrative view. Perspect Psychiatr Care. 2018;54(1):64-73.

71. Hunt JM, Sine DM. Behavioral health design guide. 7.3rd ed. Topeka: Behavioral Health Facility Consulting LC; 2018.

72. Durand MA, Lelliott $P$, Coyle N. Availability of treatment for substance misuse in medium secure psychiatric care in England A national survey. J Forensic Psychiatry Psychol. 2006;17(4):611-25.

73. Bourne R. Challenging issues in secure care. In: ClarkT, Rooprai DS, editors. Practical forensic psychiatry. London: Hodder Arnold; 2011. p. 47.

74. Care Quality Commission. Brief guide: Substance misuse services-use of blanket restrictions. London: Care Quality Commission; 2017. p. 1-4. https://www.cqc.org.uk/sites/default/files/201607_briefguide_sms-blank et-restrictions.pdf.

75. Department of Health and Social Care. Mental Health Act 1983: code of practice. Norwich: TSO (The Stationery Office); 2015.

76. Muir-Cochrane E, Oster C, Grotto J, Gerace A, Jones J. The inpatient psychiatric unit as both a safe and unsafe place: implications for absconding. Int J Ment Health Nurs. 2013;22(4):304-12.

77. Enser J, Maclnnes D. The relationship between building design and escapes from secure units. J R Soc Promot Health. 1999;119(3):170-4.

78. Penny C, Exworthy T. Human rights in secure psychiatric care. In: Dickens G, Sugarman P, Picchioni M, editors. Handbook of secure care. London: RCPsych Publications; 2015. p. 269.

79. United Nations. Universal declaration of human rights. Paris: General Assembly resolution 217 (III) A; 1948

80. Kelly BD. Dignity, mental health and human rights: coercion and the law. England: Ashgate publishing limited; 2015.

81. Beyleveld D, Brownsword R. Human dignity in bioethics and biolaw. Oxford: Oxford University Press; 2001.

82. World Health Organization. WHO-AIMS: assessment instrument for mental health systems v2.2. Geneva: World Health Organization; 2005. p. 1-92.

83. Flynn G, O'Neill C, Mclnerney C, Kennedy HG. The DUNDRUM-1 structured professional judgment for triage to appropriate levels of therapeutic security: retrospective-cohort validation study. BMC Psychiatry. 2011;11:43

84. Flynn G, O'Neill C, Kennedy HG. DUNDRUM-2: prospective validation of a structured professional judgment instrument assessing priority for admission from the waiting list for a forensic mental health hospital. BMC Res Notes. 2011;4:230

85. Müller-Isberner R, Webster CD, Gretenkord L. Measuring progress in hospital order treatment relationship between levels of security and $C$ and $R$ scores of the HCR 20. Int J Forensic Ment Health. 2007;6(2):113-21. 
86. O'Dwyer S, Davoren M, Abidin Z, Doyle E, McDonnell K, Kennedy HG. The DUNDRUM Quartet: validation of structured professional judgement instruments DUNDRUM-3 assessment of programme completion and DUNDRUM-4 assessment of recovery in forensic mental health services. BMC Res Notes. 2011:4:229.

87. Salize HJ, Lavikainen J, Seppanen A, Gjocaj M. Developing forensic mental healthcare in kosovo. Front Public Health. 2014;2:26.

88. McKenna B, Furness T, Dhital D, Park M, Connally F. Recovery-oriented care in a secure mental health setting: "striving for a good life". J Forensic Nurs. 2014;10(2):63-9.

89. Kennedy HG, O'Neill C, Flynn G, Gill P. The Dundrum Toolkit. Dangerousness, understanding, recovery and urgency manual (The Dundrum Quartet) V1.0.21 (18/03/10). Four structured professional judgment instruments for admission triage, urgency, treatment completion and recovery assessments. Trinity College Dublin. 2010:1-69.

90. Andersson M, Svennerlind C, Malmqvist I, Anckarsäter H. New Swedish forensic psychiatric facilities: visions and outcomes. Facilities. 2013;31(1/2):24-38.

91. Jansman-Hart EM, Seto MC, Crocker AG, Nicholls TL, Côté G. International trends in demand for forensic mental health services. Int J Forensic Ment Health. 2011;10(4):326-36.
92. Allison S, Bastiampillai T, Licinio J, Fuller DA, Bidargaddi N, Sharfstein SS. When should governments increase the supply of psychiatric beds? Mol Psychiatry. 2017;23:796.

93. Hodgins S, Müller-Isberner R, Allaire J-F. Attempting to understand the increase in the numbers of forensic beds in Europe: a multi-site study of patients in forensic and general psychiatric services. Int J Forensic Ment Health. 2006;5(2):173-84.

94. Forde R, Norvoll R, Hem MH, Pedersen R. Next of kin's experiences of involvement during involuntary hospitalisation and coercion. BMC Med Ethics. 2016;17(1):76.

95. Ocloo J, Garfield S, Dawson S, Dean Franklin B. Exploring the theory, barriers and enablers for patient and public involvement across health, social care and patient safety: a protocol for a systematic review of reviews. BMJ Open. 2017;7(10):e018426.

96. Chaleby K. Forensic psychiatry in Islamic jurisprudence. London: The International Institute of Islamic thought; 2001.

97. Wagenaar $\mathrm{C}$. The architecture of hospitals. Rotterdam: NAi Publishers; 2006.

98. Fazel S, Fiminska Z, Cocks C, Coid J. Patient outcomes following discharge from secure psychiatric hospitals: systematic review and meta-analysis. $\mathrm{Br}$ J Psychiatry. 2016;208(1):17-25.
Ready to submit your research? Choose BMC and benefit from:

- fast, convenient online submission

- thorough peer review by experienced researchers in your field

- rapid publication on acceptance

- support for research data, including large and complex data types

- gold Open Access which fosters wider collaboration and increased citations

- maximum visibility for your research: over 100M website views per year

At BMC, research is always in progress.

Learn more biomedcentral.com/submissions 